\title{
Application of Modified MAR Model in Barnai River Basin, NW Bangladesh: A Performance Study
}

\author{
Mohammad Iquebal Hossain ${ }^{1,2}$, Niamul Bari ${ }^{1}$, Shafi Uddin Miah ${ }^{1}$, Mohammad Ferozur Rahaman ${ }^{3}$, \\ Chowdhury Sarwar Jahan ${ }^{4, *}$
}

${ }^{1}$ Department of Civil Engineering, Rajshahi University of Engineering \& Technology, Rajshahi, Bangladesh

${ }^{2}$ Barind Multipurpose Development Authority, Rajshahi, Bangladesh

${ }^{3}$ Institute of Environmental Science, University of Rajshahi, Rajshahi, Bangladesh

${ }^{4}$ Department of Geology and Mining, University Rajshahi, Rajshahi, Bangladesh

\section{Email address:}

Iquebal_hossain@yahoo.com (M. I. Hossain), niamulbari@gmail.com (N. Bari), shafi_ruet@yahoo.com (S. U. Miah), feroz90ru@gmail.com (M. F. Rahaman), sarwar_geolog@yahoo.com (C. S. Jahan)

${ }^{*}$ Corresponding author

\section{To cite this article:}

Mohammad Iquebal Hossain, Niamul Bari, Shafi Uddin Miah, Mohammad Ferozur Rahaman, Chowdhury Sarwar Jahan. Application of Modified MAR Model in Barnai River Basin, NW Bangladesh: A Performance Study. Hydrology. Vol. 7, No. 2, 2019 , pp. 24-31. doi: 10.11648/j.hyd.20190702.11

Received: April 20, 2019; Accepted: May 23, 2019; Published: July 1, 2019

\begin{abstract}
Present study aims to evaluate performance analysis of modified recharge well (RW) technique of the Managed aquifer Recharge (MAR) models for rain water from rooftop of office building and that of runoff water from Kharoil Beel (Swamp) harvesting approach in Barnai river basin, north-western part of Bangladesh. In the area, the lower amount of rainfall than country-wide average as well as less infiltration capacity of thick top clay layer lies above the potential aquifer at higher depth put constrain for groundwater resource development against its ever increasing demand day by day along with limited scope to conserve surface water in rivers, Kharies (canals), Beels etc. The performance of modified MAR model for recharge rate calculation with a goal to restore declining trend of groundwater level (GWL) are found good without any quality hazard. Moreover, for continuous operation and better performance of MAR model, regular monitoring and maintenance are necessary along with in-depth research activities to address the burning water scarcity for drinking and irrigation management issue as viable option in sustainable way.
\end{abstract}

Keywords: Managed Aquifer Recharge, Rainwater Harvesting, Recharge Well, Barnai River Basin, NW Bangladesh

\section{Introduction}

Water is one of the most valuable natural resources which support human life and their socio-economic development. Presently groundwater based irrigation is adopted to cultivate high-yielding rice variety during dry season in South Asia especially in Bangladesh - the fourth biggest rice-producing country in the world [1-2]. Here agriculture contributes nearly $15 \%$ of the GDP as rice crops cover $75 \%$ of the cropped areas and contribute over $95 \%$ to the total food grain production. The significant growth in the country's irrigated agriculture has happened in the past decade which resulted ever increasing demand of finally leads to water shortage [34]. Like other natural calamities and disasters such as floods or cyclones in coastal and most part of the country [5-7], its northwestern part is affected more severely by drought when monsoon ends. Moreover, the unsustainable groundwater withdrawal for integrated agricultural practices is increasing, particularly in the agro-based granary in the country's northwestern part popularly known as 'Barind' with an area of $7,500 \mathrm{~km}^{2}$. Physiographically the Barind area is characterized by two distinct landforms: the Barind Tract and the floodplains. The Tract - a dome shaped horst block of Pleistocene age [8] has comparatively high elevation (47 m above MSL in its central part), and parallelly bordered by floodplain of river valleys (11 $\mathrm{m}$ above MSL) like the Mahananda, Purnabhaba in west and that of the Barnai, Sib, Atrai etc. in the southeast. The basin in the southeast is 
characterized by step faulting having downthrown blocks towards south with numerous streams, swamps (Beels) and canals (Kharies) along the flow direction of the rivers [9]. Present study area is situated in Mohanpur Upazila in
Rajshahi district (Upazila and district are the second and third tiers of administrative units in Bangladesh) in the Barnai river basin and the location map of the area is shown in "Figure 1".

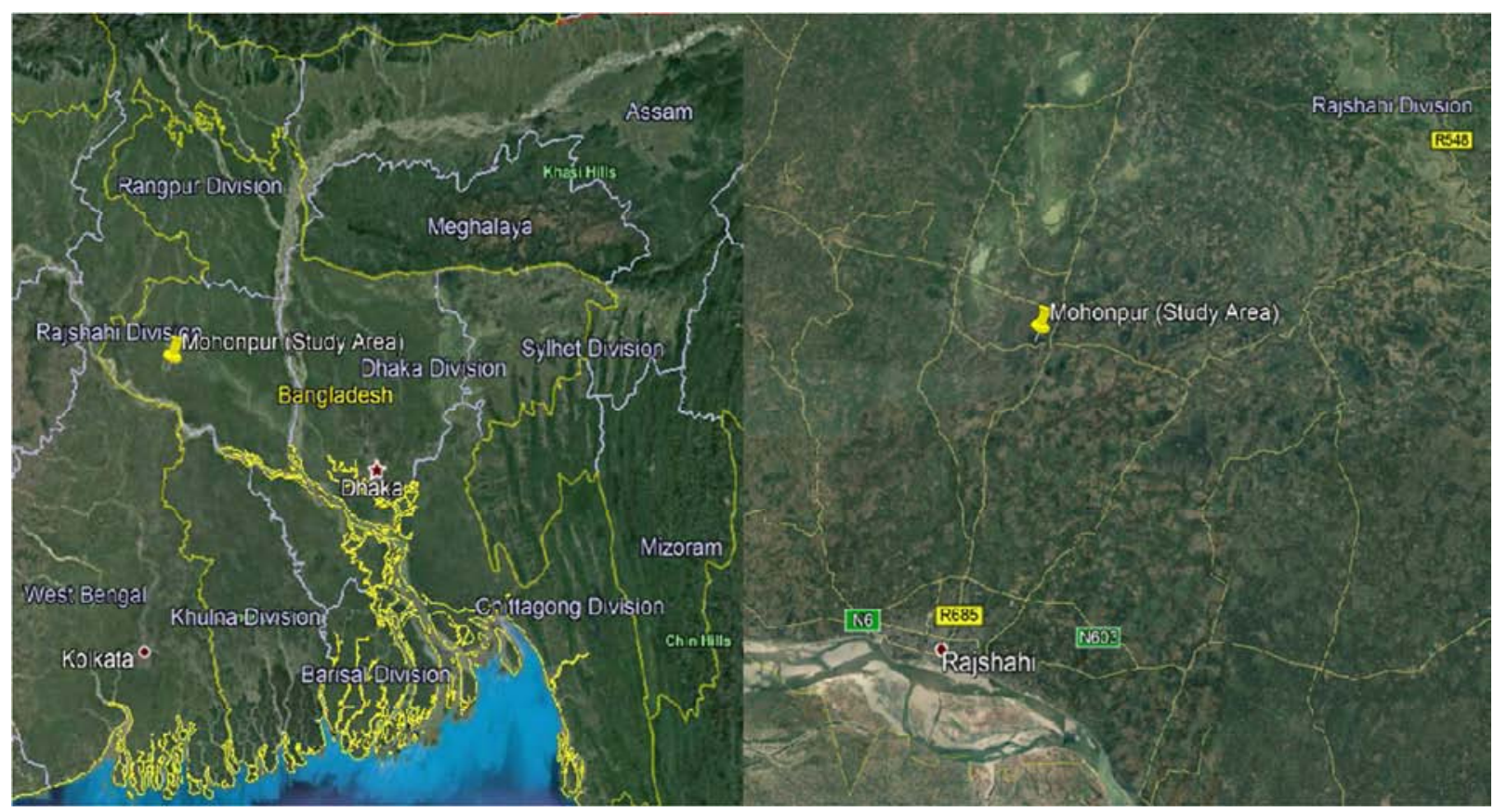

Figure 1. Location map of the study area, Mohonpur Upazila, Bangladesh.

The area enjoys mainly three seasons: winter (Nov.-Feb.) cool and dry with almost no rainfall; pre-monsoon (MarchMay) - hot and dry; and monsoon (Jun.-Oct.) - rainy. Average rainfall in the area for the period 1980-2012 is $1325 \mathrm{~mm}$ (much less than the national average of $2550 \mathrm{~mm}$ ) with significant decreasing trend $(20-23 \mathrm{~mm} /$ year $)$ [10]. The prevailing moderate to high meteorological drought risk also creeps towards semi-aridity in recent years [11]. The surface deposits of the Recent Alluvial floodplain area deposited mainly by the rivers along with their tributaries and distributaries. The accretion of rain and floodwater to groundwater during the monsoon results the rise of GWL, but afterwards recharged groundwater is partly discharged into the rivers, streams and low-lying areas with a general trend of outflow from the Barind tract towards the river basin at the end of the rainy and dry seasons [12].

The low rainfall as well as low infiltration capacity result insufficient groundwater recharge along with limited scope to conserve runoff water in rivers, Kharies, Beels etc.; and existence of potential aquifer at greater depth for large scale groundwater development makes the area a water scarce one. As the demand of groundwater for irrigation increases day by day along with meteorological variability, the stress on this resource increases and becomes acute with the extension of irrigated agriculture [13]. The recent declining trend of the groundwater table (GWT) is at a higher rate than before, and after 2002-2004, GWT did not return to its original level [10]. Moreover, the changing climatic scenario along with yearly irregular frequency and intensity of rainfall makes it difficult for planned management of water resource for
Barind area [14].

So the sustainable development of groundwater resources in the study area must be considered as the viable alternative to support the community needs and maximizing agricultural output by protecting the declining trend of GWT. Distribution of average monthly rainfall shows that the maximum rainfall occurred at July, and that of minimum occurred at December and January. The harvesting of rainwater and storage will help to ensure sustainability in water supply for domestic and other uses [15] In this context, Managed Aquifer Recharge (MAR) model, or enhanced recharge, previously known as 'artificial recharge' is the intentional diversion of surface water to the groundwater reservoir is considered as potential option to reverse the groundwater depletion, and play a vital role for sustainable irrigation [16]. Moreover, the artificial recharge to improve groundwater quantity and quality especially in Barind is strongly recommended by the Institute of Water Modelling, Bangladesh [17].

In present study, the rainwater roofs of office building of the Barind Multipurpose Development Authority (BMDA) in Mohanpur Upazila - working for irrigation management in the Barind area under the Ministry of agriculture (MoA), Govt. of Bangladesh (GoB); and runoff water from Kharoil Beel are harvested through the application of MAR model using RW with some modification and redevelopment in structural design matching with the field condition. So the aim of the present study is to design of RW with scientific basis for rainwater and runoff water harvesting to augment the groundwater resource for sustainable use where major 
challenges for MAR model application like clogging, loss of infiltration rate, etc. [16, 18-23] have taken as priority basis to make its performance as effective one.

\section{Methodology}

In present study, long term (2002-2016) rainfall and GWL monitoring data as measured by auto- groundwater level recorder from Permanent Hydrograph Stations (PHSs) have collected from BMDA office. The rainfall data shows that the maximum annual rainfall amount of $1400 \mathrm{~mm}$ and that of minimum is $773 \mathrm{~mm}$; and the long run annual average amount of rainfall is $1088 \mathrm{~mm}$ and that of monthly average rainfall is $217 \mathrm{~mm}$. The annual and monthly average rainfall pattern are shown in "Figure 2. a \& b". The maximum daily average rainfall amount is about $92 \mathrm{~mm}$.

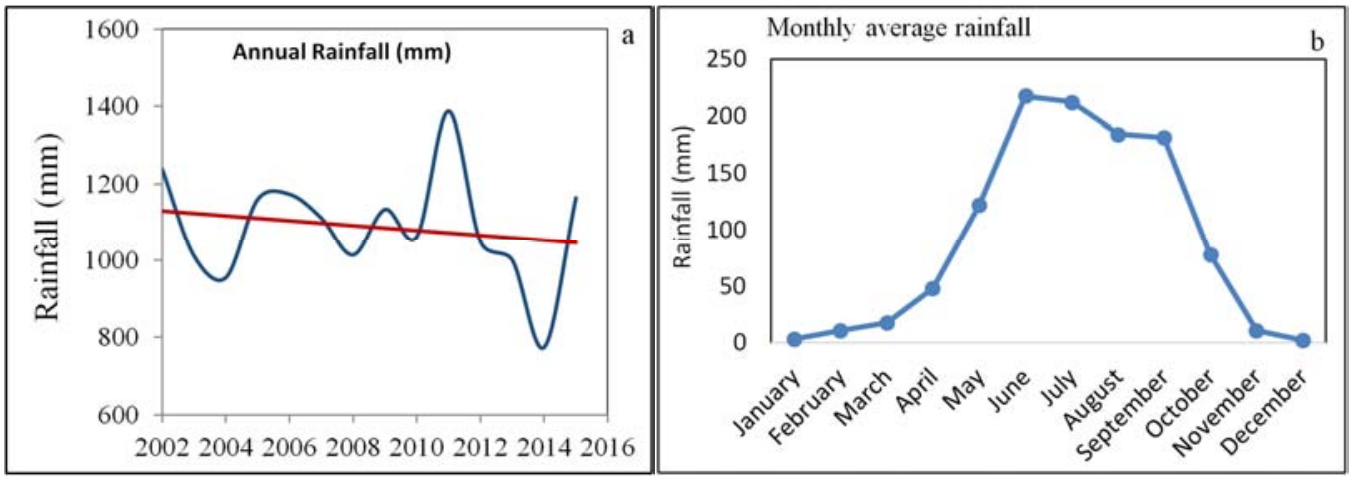

Figure 2. (a, b). Annual and Monthly average rainfall of study area.

The GWL prevails at depth (max. and min.) of 4-21 m from ground surface. The borehole litholog data at the BMDA office campus shows that $15 \mathrm{~m}$ clay overlies the aquifer zone [stratified as fine $(3 \mathrm{~m})$, medium $(6 \mathrm{~m})$ and fine (3 $\mathrm{m})$ sand lithology], and underlain by clay layer. But at Kharoil Beel, the surface lithology is comprises of $17 \mathrm{~m}$ clay layer which underlain by sandy aquifer zone $(3 \mathrm{~m}$ fine, $3 \mathrm{~m}$ fine-medium, $\mathrm{m}$ medium, and $1.5 \mathrm{~m}$ coarse sand lithological layer), and is underlain by clay layer. The lithological samples from sandy aquifer zone from the bore holes are collected and textural analyses (grain size) have been carried out. The borehole lithology along with grain size distribution curve is shown in "Figure $3 \mathrm{a}, \mathrm{b}$ ".
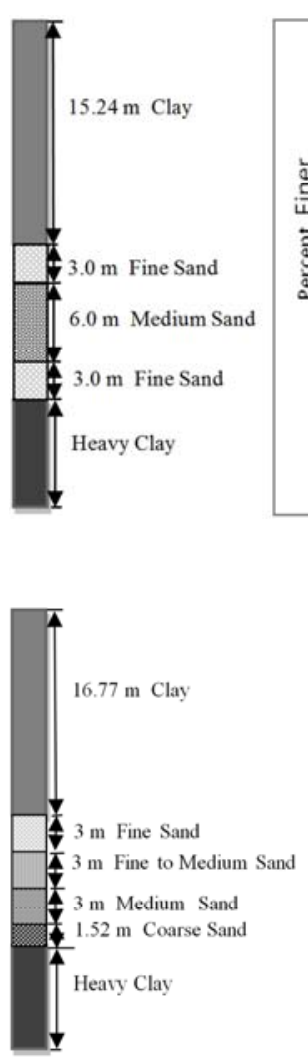

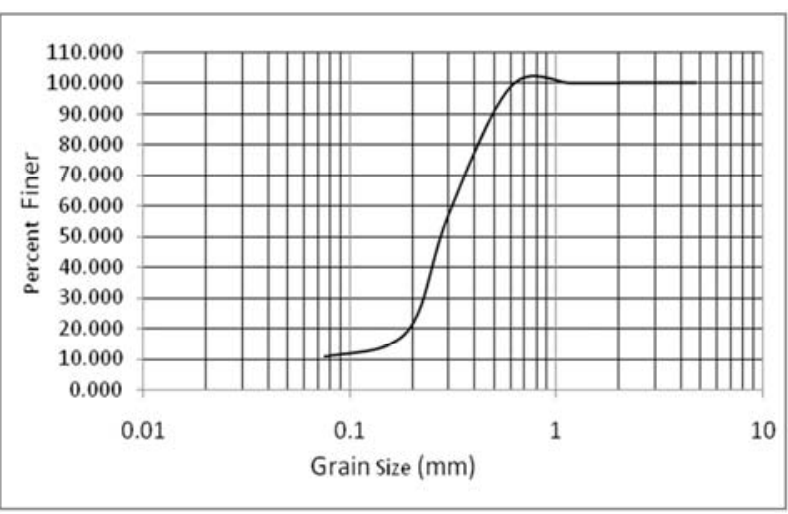

(a)

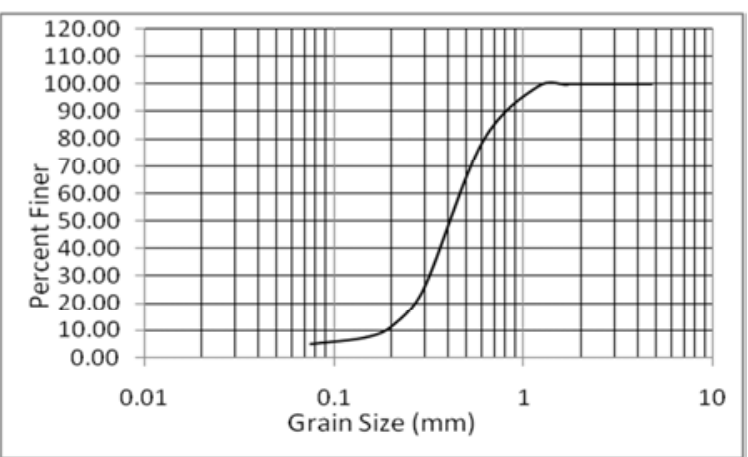

(b)

Figure 3. Borehole lithology along with grain size distribution curve of aquifer zone a) Mohanpur BMDA office campus, b) Kharoil Beel recharge wells in the study area. 
The RWs used for MAR model are designed considering textural analysis (grain size) of aquifer layer and have installed in 2016 at the BMDA Office Campus and Kharoil Beel. The recharge box for MAR model in the BMDA office campus has designed considering maximum daily average rainfall amount of $92 \mathrm{~mm}$, where coarse sand and gravel of different sizes have used as filtering materials.

The uPVC blind pipe and strainer (nominal slot width: 1.52 $\mathrm{mm}$ and open area: 20\%) acted as recharging pipe from recharge box to aquifer. The annular space between the casing assembly and the wall of the drilled hole has shrouded by $4-10 \mathrm{~mm}$ size pea gravel. For monitoring of GWL, PHS has installed nearby of respective RW.
On the other hand, the RW in Kharoil Beel, the water control and measuring structure (WCMS) (1.9 $\mathrm{m}$ inner diameter and $1.3 \mathrm{~m}$ height) has been constructed around the recharge box.

Here a number of water entrance pipes or weep holes have placed in the wall of the WCMS at a height of $0.60 \mathrm{~m}$ from the ground surface and the caps are fitted to close and open these pipes. The installed RWs along with recharge box at BMDA office campus and Kharoil Beel are shown in "Figure $4 \mathrm{a}, \mathrm{b}$ ". After installation of RWs, the groundwater recharge RR and GWL data have measured and calculated to evaluate the performance of application of MAR model in the study area.

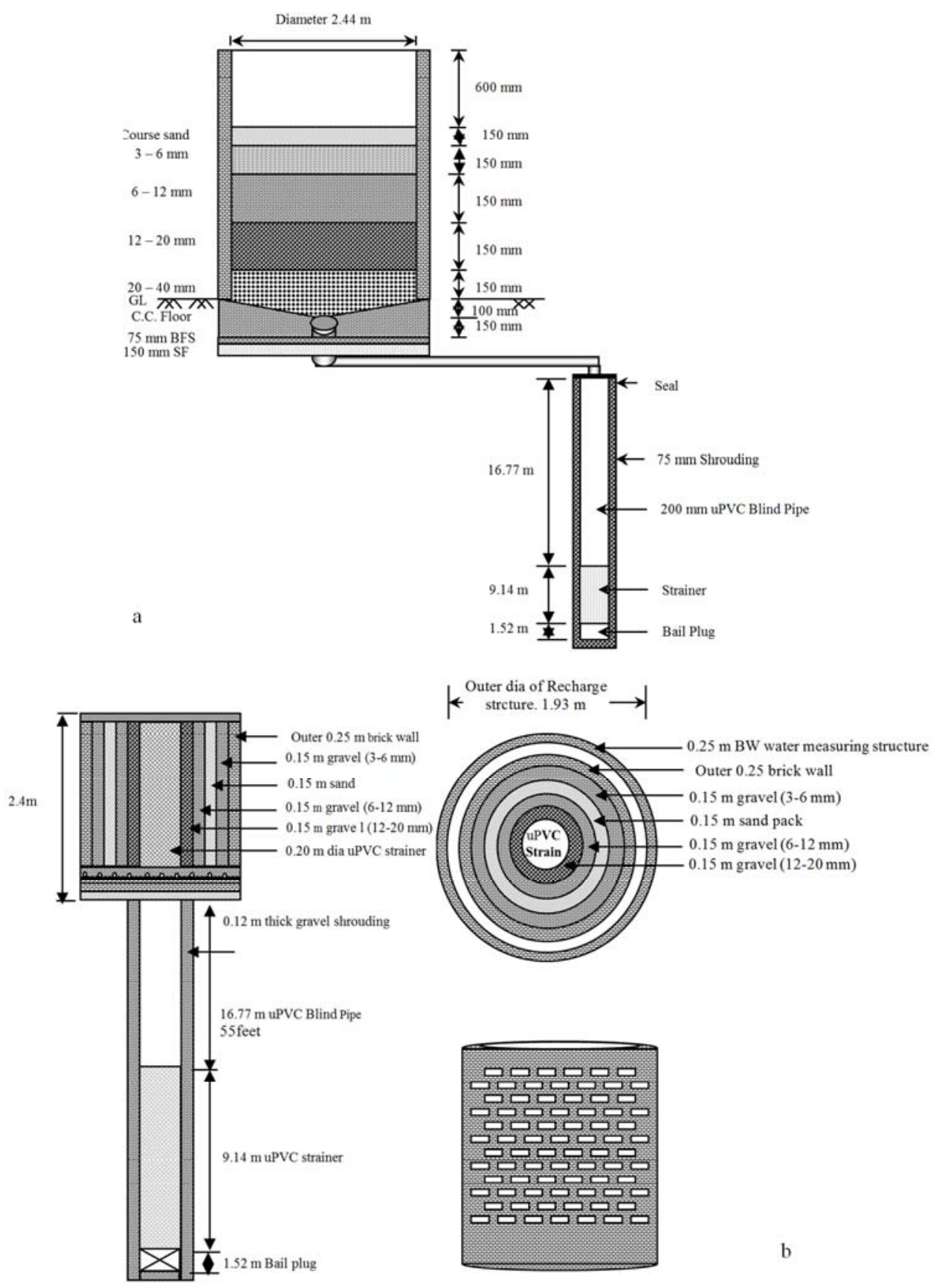

Figure 4. Schematic diagram of recharge wells with infiltration units (a) BMDA office campus for roof top rainwater harvesting (b) Kharoil Beel for runoff water harvesting in the study area. 
In order to ensure the safe drinking water for human need, groundwater samples have been collected after MAR model application at different time interval in the BMDA office campus and have been analyzed in the laboratory of BMDA for the physical parameters like $\mathrm{pH}, \mathrm{EC}$, TDS and TH, and also that of chemical parameters like $\mathrm{Fe}^{\text {total }}, \mathrm{Cl}^{-}, \mathrm{Ca}^{2+}, \mathrm{Mg}^{2+}$ and As (Table 1). On the other hand, surface water and groundwater samples before and after MAR technique application have also collected from RW in Kharoil Beel and have analyzed for parameters like Turbidity, $\mathrm{K}^{+}, \mathrm{SO}_{4}{ }^{2-}, \mathrm{NO}_{3}{ }^{-2}$, and $\mathrm{PO}_{4}^{-2}$ in the Laboratory of the Department of Public Health Engineering (DPHE) Rajshahi; NGO FORUM Dhaka; and Soil Resource Development Institute (SRDI) Rajshahi Table 1. The results of physical and chemical parameters of groundwater and surface water samples in BMDA office campus and Kharoil Beel areas have given in Table 1.

Table 1. Result of physical and chemical parameters of water samples in the study area.

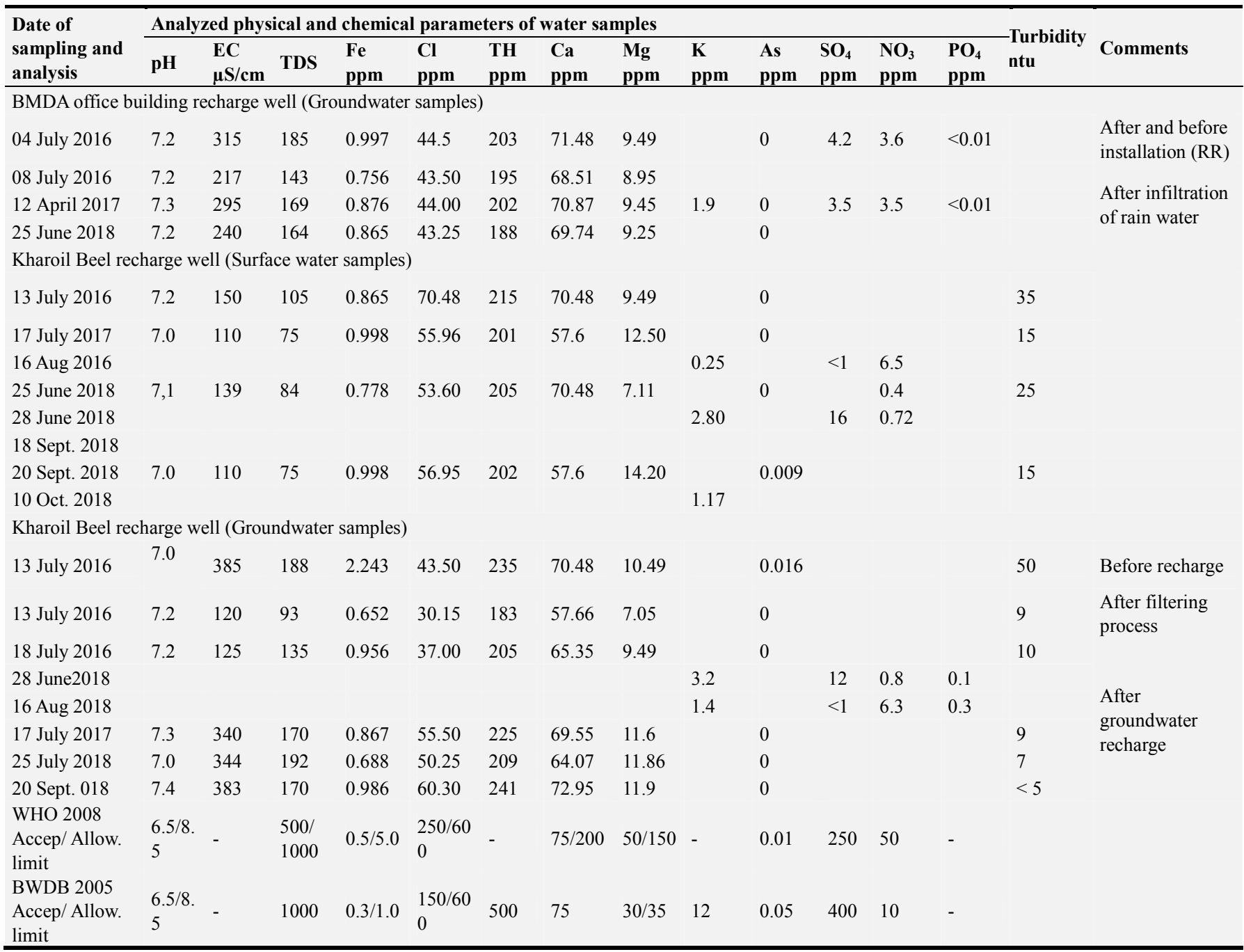

\section{Result and Discussion}

\subsection{Recharge Well in BMDA Office Campus}

During rainy season, the rain water from the roof top of the office building flows towards recharge box, then through RW and PVC pipe strainer ultimately enters into the aquifer to augment the groundwater resource. The roof top area of BMDA office building is $260 \mathrm{~m}^{2}$, so the annual recharge amount is calculated as:

Annual recharge $=(90 \%$ of average annual rainfall $\times$ Area $)$

$$
=(1088 \times 0.90 \times 260) / 1000 \mathrm{~m}^{3}=255 \mathrm{~m}^{3} \text { or } 255000 \text { liter }
$$

The hydrograph of GWL "Figure 5" shows its direct response to rainfall indicating the augmentation of groundwater resource. 


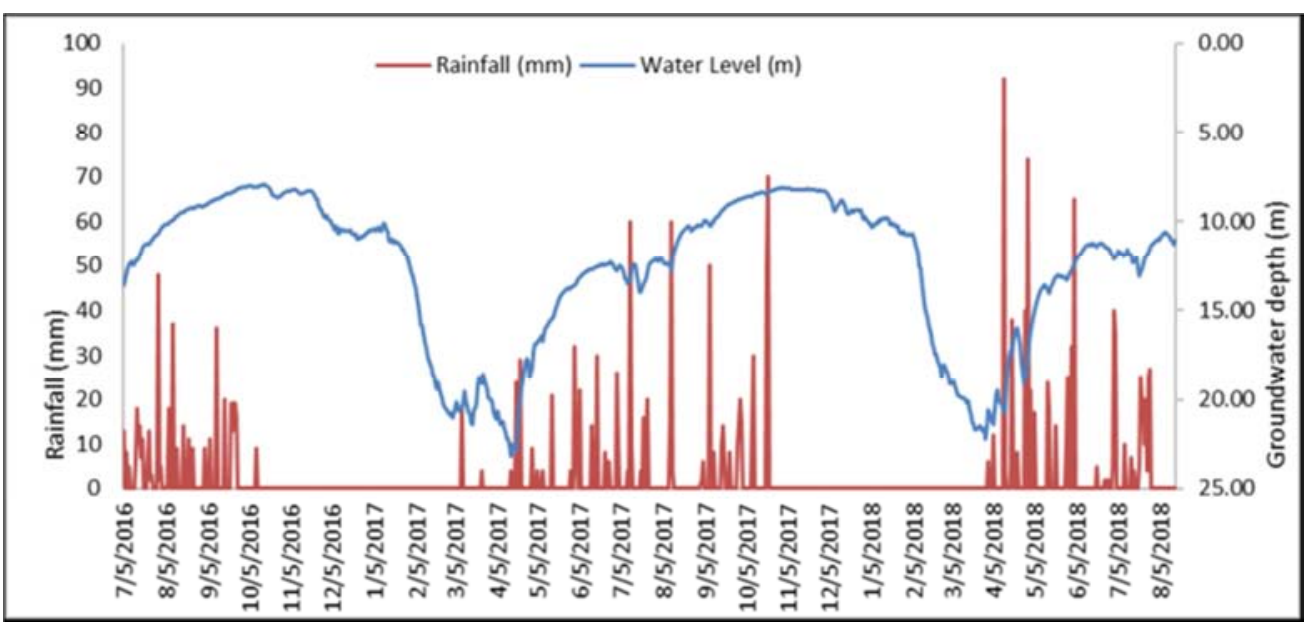

Figure 5. Relationship between rainwater and GWL in BMDA Office Campus recharge well.

The GWL declines due to less amount of rainfall in summer time (March-May) in 2018 along with overexploitation of groundwater for irrigation in agriculture in the peak period of irrigation. The analyzed physical parameters and chemical parameters Table 1 reveals that the concentration of different analyzed parameters are within the accepted limit [24-25] for drinking as well as agricultural purpose, and their concentration have reduced as a result of dilution effect after recharging process of rainwater.

\subsection{Recharge Well in Kharoil Beel}

To measure the recharge rate (RR), runoff water has been allowed to enter into the WCMS through entrance pipe. When the WCMS has filled with storm or runoff water, the entrance pipe has closed by tightening the cap. The quantity of storm water is calculated by multiplying inside water height with inner area of WCMS. The runoff water inside the structure has started to enter into aquifer, and WCMS would be empty after certain time. Thus RR has been calculated by dividing the quantity of water entered into aquifer in course of time as:

\section{$\mathrm{RR}=[($ Inner area of WCMS depth of water $) /$ time span $]$}

Table 2 shows the calculated values of RR at different time interval and found that the RW has performed well functioning. But as a result of clogging effect due to excess suspended deposits of silty material in runoff water and iron content in groundwater, the RR to aquifer has reduced.

Table 2. Calculated values of recharge rate $(R R)$ at different time interval in Kharoil Beel in study area.

\begin{tabular}{|c|c|c|c|c|}
\hline Date of Analysis & $\begin{array}{l}\text { Volume of } \\
\text { water, Q (litre) }\end{array}$ & $\begin{array}{l}\text { Time required to empty } \\
\text { WCMS, } t \text { (min.) }\end{array}$ & $\begin{array}{l}\mathbf{R R}(\mathbf{Q} / \mathbf{t}) \\
(\mathrm{L} / \mathrm{min})\end{array}$ & Comments \\
\hline 13 July 2016 & 3348 & 20 & 168 & \\
\hline 15 July 2016 & 3348 & 20 & 167 & \\
\hline 25 April 2017 & 3348 & 23 & 143 & $\begin{array}{l}\text { Recharge reduces due to clogging by excessive iron concentration in } \\
\text { native groundwater. }\end{array}$ \\
\hline 20 May 2017 & 3348 & 21 & 163 & Recharge regains due to onetime redevelopment of RW. \\
\hline 15 April 2018 & 3348 & 22 & 152 & Recharge rate reduces due to clogging by iron content in groundwater. \\
\hline 25. June 2018 & 3348 & 21 & 160 & Recharge regains by redevelopment of RW \\
\hline
\end{tabular}

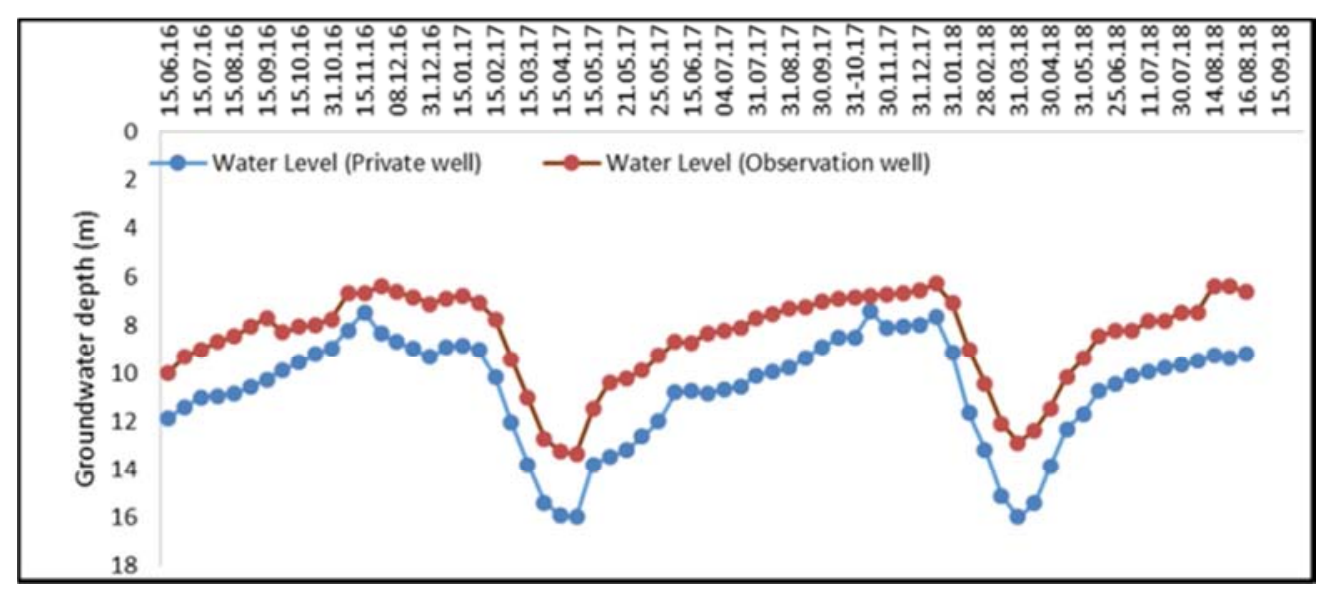

Figure 6. GWL fluctuation curve in Kharoil Beel recharge well in the study area. 
But it has regained recharge when the RW is redeveloped by pumping and backwashing. So for the continuous and better operation RW needs redevelopment at least once in a year. Moreover, the hydrograph of GWL "Figure 6" (PHSs situated at a distance of $75 \mathrm{~m}$, and a private well at a distance of about $300 \mathrm{~m}$ both in the in eastern side from the RW) shows direct response of GWL when the Beel is filled with runoff water with a height of 0.6-3.0 m, higher than that of private well. The analyzed physical and chemical parameters reveals that the concentration of different ions exist within the acceptable limit for drinking and irrigation purpose [2425 ], and the concentration of different ions have reduced due to dilution effect as a result of recharged process of rainwater.

\section{Conclusions}

The application of MAR model using RW technique with some modification and redevelopment in structural design due to prevailing challenges like clogging, loss of infiltration rate etc., in the study area is an effective approach and is functioning well. The scenario of GWL due to rainwater and runoff water harvesting has positive impact on augmentation of groundwater resource, and is within the acceptable limit for drinking and irrigation purposes as far as quality concern. Moreover, for the sustainable and better operation of the MAR model continuous and regular monitoring and maintenance are essential for reversing the permanently declining trend of GWL due to ever increasing groundwater resource demand in this drought-prone agro-based granary. Finally more research on MAR model should be carried to make it effective and fruitful in context of water scarcity in Barind area, Bangladesh.

\section{References}

[1] C. A. Scott, and B. Sharma, "Energy supply and the expansion of groundwater irrigation in the Indus-Ganges Basin". International Journal of River Basin Management. 2009, 7 (2) pp. 119-124, doi: 10.1080/15715124.2009.9635374.

[2] IRRI (International Rice Research Institute), World rice statistics (WRS), Manila, Philippines, 2010.

[3] M. De Villiers, "Water: the fate of our most precious resource", Mariner Books, Houghton, Mifflin, Boston, 2000.

[4] G. Tsakiris, "Water resources management trends, prospects and limitations", In: Proceedings of the EWRA symposium on water resources management: risks and challenges for the $21 \mathrm{st}$ century, 2-4 September 2004, Izmir, pp. 1-6.

[5] H. Brammer, "Drought in Bangladesh: lessons for planners and administrators", Disasters, 1987, 1 (1), pp. 21-29.

[6] D. Alexander, "Changing perspectives on natural hazards in Bangladesh", Natural Hazards Observation Journal, 1995, 10 (1), pp. 1-2.

[7] K. B. S. Rasheed, "Bangladesh Resource and Environmental Profile Hardcover," (https://www.amazon.com/BangladeshResource-Environmental-Profile Sajjadur/dp /B0062 VHID),
2008.

[8] R. A. Khandoker, "Origin of elevated Barind Madhupur areas, Bengal Basin: Results of neotectonic activities," Bangladesh Journal of Geology, 1987, vol. 6, pp. 1-9.

[9] C. S. Jahan, and M. Ahmed, "Flow of groundwater in the Barind area, Bangladesh: implication of structural framework" Journal of Geological Society of India, 1997, 50, pp. 743-752

[10] C. S. Jahan, A. T. M. S. Rahman, Q. H. Mazumder, and M. Kamruzzaman, "Adaptation for Climate Change Effect on Groundwater Resource through MAR Technique in Drought Prone Barind Area, Rural Bangladesh,” In S. M. Ali (Ed.), Bangladesh: Combating Land Degradation and Drought. Dhaka: Series-II, Department of Environment (DoE), Ministry of Environment (MoEF), Government of Bangladesh, 2015, pp. 61-83

[11] C. S. Jahan, Q. H. Mazumder, and T. M. M. Islam, "Impact Evaluation of an Irrigation Project Based on Meteorological Data and Groundwater Hydrograph: A Case Study of BIADP, NW Bangladesh," Published in the Proceedings of the XXXIX IAH Congress (IAH 2008), Toyama, Japan. Held on 26 October to 1 November 2008.

[12] C. S. Jahan, Q. H. Mazumder, M. I. Adham, M. M. A. Hossain, H. Al-Mamunul, "Study on Groundwater Recharge Potentiality of Barind Tract, Rajshahi District, Bangladesh Using GIS and Remote Sensing Technique," Journal of Geological Society of India, 2010, vol. 75, pp. 432-438.

[13] M. F. Rahaman, C. S. Jahan, R. Arefin, and Q. H. Mazumder, "Groundwater Potentiality Study in Drought Prone Barind Tract, NW Bangladesh using Remote Sensing and GIS," Groundwater for Sustainable Development, 2018, Doi. 10.1016/j.gsd.2018.11.006

[14] A. T. M. S. Rahman, M. Kamruzzaman, C. S. Jahan, Q. H. Mazumder, A. Hossain, "Evaluation of spatio-temporal dynamics of water table in NW Bangladesh - an integrated approach of GIS and statistics," Sustainable Water Resources Management, 2016, 2 (3), pp. 297-312, doi: 10. 1007/s40899016-0057-4

[15] M. F. Rahaman, C. S. Jahan, and Q. H. Mazumder, "Rainwater harvesting to alleviate water scarcity in droughtprone Barind Tract, NW, Bangladesh: a case study," Sustainable Water Resources Management, 2019, doi.org/10.1007/s40899-019-00311-8.

[16] British Geological Survey (BGS) "The effectiveness of artificial recharge of groundwater: a review", 2002.

[17] IWM, "Groundwater Resources Study and Decision Support System Development of Rajshahi, Naogaon, Chapai Nawabganj, Pabna and Natore Districts and Also Remaining District of Rajshahi Division through Mathematical Model Study for Barind Integrated Area Development Project" Phase-III, Final Report, 2012, Vol. 1.

[18] M. P. O'Hare, “Artificial Recharge of Groundwater. Proceeding of the Second International Symposium on Artificial Recharge of Groundwater", (http:llewr.cee.vt.edu/environmental/teach/gwprimer/rechargel recharhgtme.1), 1986.

[19] N. N. Kumar, "Artificial Recharge of groundwater" (http://www.cee.vt.edu/programm_areas/envirommental/tech/ gwprimer/recharge/recharge.html), 1997. 
[20] Central Ground Water Board (CGWB) Guide on Artificial Recharge to Groundwater. Ministry of Water Resources, New Delhi, India. (cgwb.gov.in/documents/ArtificialRechargeGuide.pdf), 2000.

[21] H. Bouwer, "Artificial Recharge of groundwater: hydrogeology and engineering," Hydrogeology Journal, 2002, Vol. 10, pp. 121-142.

[22] UNESCO-IAH, "Strategies for Managed Aquifer Recharge (MAR) in semi-arid areas" Edited by: Gale, I. UNESCO, Paris, 2005, pp. 30.
[23] A. K. Bhattacharya, "Artificial Groundwater Recharge with a special reference to India," International Journal of Research and Reviews in Applied Sciences, 2010, Vol. 4, pp. 2.

[24] WHO (World Health Organization), "Guidelines for Drinkingwater Quality" Third Edition, Volume 1, World Health Organization, Geneva, 2004.

[25] Bangladesh Drinking Water Standard (BDWS), Bangladesh Drinking Water Standard, Dhaka, Bangladesh, 2005. 